\title{
CONSTITUIÇÃO, FEDERAÇÃO E PROPOSTAS PARA O NOVO PLANO NACIONAL DE EDUCAÇÃO: ANÁLISE DAS PROPOSTAS DE ORGANIZAÇÃO NACIONAL DA EDUCAÇÃO BRASILEIRA A PARTIR DOO REGIME DE COLABORAÇÃO
}

\author{
Gilda Cardoso de Araujo*
}

\begin{abstract}
RESUMO: O objetivo do artigo é analisar a relação entre o processo de inclusão do município, como ente federado com competência para constituir sistemas próprios de ensino em regime de colaboração, e as propostas de construção do Sistema Nacional de Educação dos documentos que serviram de referência à CONAE para a elaboração no novo Plano Nacional de Educação. Buscamos conceituar e contextualizar o regime de colaboração, a partir do princípio da subsidiariedade, a fim de demonstrar as várias inconsistências nas propostas apresentadas nos documentos. As conclusôes indicam a incoerência, a imprecisão e a inconsistência quanto à prescrição do regime de colaboração para a educação, o que pode resultar em mais um imbróglio no já suficientemente complexo arranjo federativo brasileiro.
\end{abstract}

Palavras-chave: Federalismo e educação. Sistema Nacional de Educação. Regime de colaboração. Plano Nacional de Educação (2011-2020).

CONSTITUTION, FEDERATION AND PROPOSALS FOR THE NEW NATIONAL PLAN FOR EDUCATION: AN ANALYSIS OF THE PROPOSED NATIONAL ORGANIZATION OF THE BRAZILIAN EDUCATION SYSTEM BASED ON COLLABORATION

ABSTRACT: This paper analyzes the relationship between the process that turns municipalities into federal entities qualified to establish their own education systems based on collaboration and the proposals to build a National Education System contained in

Doutora em Educação e professora-adjunta do Programa de Pós-Graduação em Educação da Universidade Federal do Espírito Santo (UFES). E-mail: gilda.vix@terra.com.br 
the documents used at CONAE to work out the new National Plan for Education. Based on the principle of subsidiarity, it seeks to conceptualize and contextualize collaboration to unveil the various inconsistencies of such proposals. Results point out inconsistency, inaccuracy and incoherence as for the prescription of collaboration in education, which can result in an imbroglio over the already sufficiently complex Brazilian federal arrangement.

Key words: Federalism and education. National Education System. Collaboration system. National Plan for Education (20112020).

\section{Introdução}

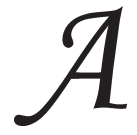

Constituição Federal de 1988 pretendeu romper a lógica do movimento pendular entre centralização e descentralização, associando um dos padróes de organização federativa mais descentralizados das federações existentes no mundo com a ideia de um sistema nacional de ensino equânime, mediante a regulamentação do regime de colaboração. Além disso, formalizou uma notória especificidade em relação às demais federações do mundo: a inclusão do município como um terceiro ente federado.

Entretanto, o debate e a normatização relativa à distribuição das competências e recursos foram geralmente tratados de uma maneira pontual, fragmentada e imediata, sem uma análise sobre os conflitos federativos que estão na sua base. A questão da distribuição das competências e dos recursos entre os entes federados diz respeito não só aos fundamentos do federalismo, como também à forma que este assumiu na história política brasileira, pois tem relação direta com as disputas entre o nacional e o local e os interesses das elites políticas em um ou outro desses vetores.

A organização da Conferência Nacional de Educação (CONAE), visando à ampla mobilização em torno da elaboração do novo Plano Nacional de Educação (PNE), buscou enfrentar esses entraves federativos, propondo-se a debater a construção de um "Sistema Nacional Articulado de Educação". Para tanto, associou a organização da educação nacional com a necessidade da regulamentação do regime de colaboração, previsto no parágrafo único do artigo 23 da Constituição Federal de 1988. 
Todavia, em que pese esse notável e louvável esforço de mobilização democrática, a metodologia pulverizada das conferências preparatórias e a falta de acúmulo teórico e histórico sobre o instituto jurídico do regime de colaboração na área de educação podem contribuir para tornar a dinâmica federativa ainda mais complexa do que se configura na atualidade.

Nesse sentido, a história tem muito a nos indicar. Por isso, neste artigo, iniciamos com uma análise sobre o processo de inclusão do município como ente federado com competência para constituir sistemas próprios de ensino, em regime de colaboração, na Assembléia Nacional Constituinte de 1987. Nesse item, destacamos os interesses imediatos e pouco articulados à reflexão sobre políticas públicas nacionais, a partir da bandeira da descentralização de perfil municipalista. $\mathrm{Na}$ sequência, analisamos, do ponto de vista histórico e conceitual, o regime de colaboração e sua articulação com o princípio da subsidiariedade, que não foi debatido nos documentos da CONAE ou em qualquer outra instância de defesa da regulamentação do regime de colaboração. Enfim, discutimos os documentos que deram suporte à CONAE e o Documento Final da mesma, indicando a incoerência, a imprecisão e a inconsistência dos mesmos quanto à prescrição do regime de colaboração para a educação, o que pode resultar em mais um imbróglio no já suficientemente complexo arranjo federativo brasileiro.

\section{Federação e organização do ensino no processo constituinte}

O governo de José Sarney, constituindo um governo civil após 21 anos de regime militar, significou o crescimento das demandas pela alteração do desenho tributário e colocou em pauta a questão federativa. A Assembléia Constituinte traduziu essas demandas e evidenciou essa pauta:

(...) os princípios que a nortearam foram dados pela disposição, de um lado, de promover a descentralização tributária e, de outro, de coibir a liberdade do governo federal de manipular as questôes ligadas à área orçamentária e intervir na capacidade de arrecadação dos governos estaduais e municipais. (Lopreato, 2002, p. 107)

Foi nesse cenário político e econômico que se retomou uma Federação de perfil tridimensional, ${ }^{1}$ com base nas demandas e na atuação de 
instituições municipalistas, como o Instituto Brasileiro de Administração Municipal (IBAM), tributário da Associação Brasileira dos Municípios (ABM) na década de 1940.

A atuação do IBAM na configuração explícita de uma Federação de perfil tridimensional na Constituição Federal de 1988 pode ser evidenciada nos relatórios do processo constituinte, das comissões e das subcomissões. ${ }^{2}$

No relatório da Comissão do Estado/Subcomissão da União, Distrito Federal e Territórios, cuja autoria coube ao deputado Sigmaringa Seixas, ficam evidenciados aspectos importantes quanto à configuração do federalismo no futuro texto constitucional. O primeiro deles é a denúncia de que, na vigência da Constituição de 1967, o modelo federativo teria se tornado altamente concentrador de poderes e competências na União, não consolidando a autonomia dos estados nem dos municípios, pelo excessivo centralismo fiscal (Brasil, 1987a).

Já no relatório da Comissão do Estado/Subcomissão de Municípios e Regiões, de autoria do deputado Aloysio Chaves, fica evidente a defesa de uma Federação tridimensional e a influência decisiva do IBAM nessa defesa (Brasil, 1987b).

Fora a evidente influência do IBAM, é curioso observar que o mesmo argumento utilizado para a manutenção do federalismo dual na Subcomissão da União, Distrito Federal e Territórios, sob a relatoria do deputado Sigmaringa Seixas, foi também utilizado pelo deputado Aloysio Chaves, no relatório da Subcomissão de Municípios e Regiōes, para a defesa do federalismo tridimensional: a nossa tradição jurídica e política. Outra questão curiosa é como foram absolutamente desprezados os aspectos relativos ao modelo federativo vigente em outros países e, sobretudo, a questão dos recursos e competências dos entes federados nessa perspectiva tridimensional, dada a trajetória de tutela e atrelamento dos municípios brasileiros ao governo central. Diante dessa realidade, apenas a evocação de uma suposta "originalidade" dos constituintes do passado, que teriam, de algum modo, preparado a fórmula constitucional da Federação tridimensional, foi suficiente para a sua inscrição no novo texto.

Souza (2001), ao analisar o processo decisório na Assembléia Constituinte relativo às mudanças na Federação, buscou entender as razões pelas quais um país, com uma agenda de problemas que requer 
políticas nacionais, decidiu descentralizar os poderes político e financeiro. A autora conclui que a decisão pela descentralização federativa de perfil municipalista foi marcada por premissas normativas, em lugar de avaliações sobre suas consequências na correlação de forças dentro da Federação.

A posição pela descentralização de perfil municipalista não teve, contudo, acolhida na Subcomissão "Da educação, cultura e esportes"/ Comissão "Da família, da educação, cultura e esportes, da ciência e tecnologia e da comunicação", cujo relator foi o senador João Calmon. $\mathrm{Na}$ parte relativa à organização do ensino, o relatório da subcomissão destaca várias sugestōes e emendas, no sentido de tornar o município responsável pela oferta do ensino elementar e da educação infantil, mas enfatizava também que a Associação Nacional de Educação e o Conselho Federal de Educação, entre outras entidades, além do Fórum Nacional em Defesa da Escola Pública, encaravam com muita cautela a municipalização do ensino, devendo ser assegurados, em primeiro lugar, efetivos recursos para que os mesmos pudessem ofertar essas etapas de escolarização com boas condições (Brasil, 1987c).

Além da autonomia municipal, com a definição explícita do município como ente federado, também foi prevista no texto constitucional a organização de sistemas de ensino da União, dos estados, do Distrito Federal e dos municípios (art. 211), em regime de colaboração a ser regulamentado por lei complementar, segundo o disposto no parágrafo único do artigo $23 .^{3}$

Essa nova configuração do federalismo brasileiro trouxe duas enormes complicaçôes para a engenharia institucional e política do país: a primeira relativa ao tamanho e à heterogeneidade da Federação brasileira, constituída, em sua maioria, por estados e municípios que sobrevivem com repasses dos fundos de participação, e a segunda relativa à falta de clareza e regulamentação do que consistiria o regime de colaboração.

Nesse cenário observamos que, após 21 anos da promulgação da Constituição Federal, tivemos "minipactos" no sentido de amenizar a assimetria e o caráter predatório e competitivo da Federação erigida. $\mathrm{Na}$ área de educação, podemos citar as políticas de criação de fundos por meio de emendas constitucionais que tentaram, a um só tempo, resolver o problema da assimetria dentro dos municípios de um mesmo estado e regulamentar, ainda que de forma precária, o regime de 
colaboração. Também foi possível observar ações de coordenação da União com a indução de políticas para a área de educação, traduzidas, erroneamente, como colaboração, como é o caso dos testes em larga escala, das definições curriculares e, recentemente, do Plano de Desenvolvimento da Educação e do Plano de Açôes Articuladas.

Todavia, esses "minipactos" não incidem sobre a questão histórica, estrutural e nevrálgica da organização da educação nacional que é a constituição de um Sistema Nacional de Educação (SNE), cujas bases são duas medidas vigorosas do ponto de vista político e institucional: uma reforma tributária, que elimine as brutais desigualdades regionais, e a regulamentação do regime de colaboração, ou seja, duas medidas que alteram o modelo do federalismo brasileiro, do ponto de vista fiscal e do ponto de vista jurídico-político.

Regime de colaboração e subsidiariedade: contextos e conceito

A falta de regulamentação do regime de colaboração no Brasil não ocorreu por falta de tentativas. Foram elaborados cinco projetos de lei que abordam o regime de colaboração na educação, todos de iniciativa do Legislativo. Entretanto, não houve debate sobre a matéria, uma vez que foram arquivados sem relatoria ou porque não estavam relacionados à matéria, ou por fim de legislatura, ou por trâmite indevido (Cassini, 2010).

De fato, trata-se de um instituto relativamente fácil de proclamar, mas muito complexo de se debater teórica e juridicamente. Se existe consenso, entre os estudiosos do federalismo, de que não há uma Federação igual à outra, isso não significa que não existem características específicas desse arranjo político institucional: a permanente tensão entre simetria e assimetria, unidade e diversidade, e entre união e autonomia (Kugelmas, 2001).

As variações de contexto histórico do federalismo concorreram para muitas flexibilizaçôes conceituais, de maneira que é possível identificar três matrizes, segundo o nível das relações intergovernamentais entre os entes federados: o federalismo dual, modelo original dessa forma de organização político-administrativa, elaborado e implementado nos Estados Unidos; o federalismo centralizado, em que as unidades subnacionais são agentes administrativos do governo central, como na 
Venezuela, na Áustria e na Índia; e o federalismo cooperativo, em que os entes federados e o governo nacional têm ação conjunta e capacidade de autogoverno, como na Alemanha (Lijphart, 2003).

O federalismo dual tem por base, essencialmente, a competição entre os entes federados, ao passo que o federalismo centralizado subordina as unidades subnacionais às demandas do Estado nacional. No Brasil, é possível encontrar essas duas matrizes de federalismo desde sua instituição, em 1891, de forma simultânea ou não, como ocorreu nos períodos ditatoriais.

Os fundamentos da Constituição Federal promulgada em 5 de outubro de 1988 estão ancorados no federalismo cooperativo, cuja intenção é equilibrar os conflitos federativos e garantir a mesma qualidade de vida para todos os cidadãos, independente da região, estado ou cidade em que habitam. Desse modo, sua premissa é o equilíbrio das tensões entre simetria e assimetria, unidade e diversidade e união e autonomia.

A matriz cooperativa do federalismo ${ }^{4}$ surgiu na era de Oton Von Bismark $(1880)^{5}$ e foi consolidada na Constituição de 1949 , cuja premissa era livrar a Alemanha da experiência traumática do nazismo. Essa matriz teve forte inspiração social (ascensão do Estado de bem-estar na Europa) e religiosa, pois, na década de 1930, a Encíclica Quadragesimo Anno - ainda que mantivesse forte inspiração da Encíclica Rerum Novarum, de 1891, mediante a defesa da propriedade privada - afirmava o caráter suplementar ou subsidiário do Estado no combate às injustiças sociais.

Oswald Von Nell-Breuning ${ }^{6}$ relacionou o federalismo com a subsidiariedade, ao articular o primeiro à aplicação do princípio da subsidiariedade no plano político, e essa combinação foi introduzida, por influência de Konrad Adenauer, na Constituição alemã de 1949, que se consolidou sob a hegemonia do Partido Democrata Cristão. Assim se configurou a matriz cooperativa alemã, baseada no princípio de subsidiariedade (Gabardo, 2009; Camargo, 2001).

Camargo (2001), ao analisar o federalismo na Alemanha, destaca algumas características importantes: a) a inexistência de separação entre os entes federados, funcionando o princípio da subsidiariedade; b) há mecanismos redistributivos entre estados e regiões pela instância federal; c) há mecanismos de cooperação horizontal entre 
Constituição, Federação e propostas para o novo Plano Nacional de Educação...

os kreis (unidades microrregionais equivalentes aos municípios em que se aplica o princípio da subsidiaridede; d) o nível de cooperação por excelência é o da sociedade civil (indivíduo como cidadão, família e organizações civis), relativamente despolitizada e voltada para atividades de interesse local; e) o Bundesrat é um mecanismo de cooperação relevante, uma vez que é o órgão de representação dos governos estaduais que neutraliza as forças centrífugas dos estados.

Dessa forma, é possível constatar a forte presença do princípio da subsidiariedade no regime de colaboração alemão. A subsidiariedade é uma ideia e um princípio que consiste na defesa de políticas diretamente conduzidas pela autoridade e/ou instituição mais próxima do cidadão. Dessa forma, a prioridade das iniciativas, do ponto de vista das políticas, seria a da sociedade sobre o Estado e, na esfera estatal, a preponderância da instância local sobre o estado e deste sobre o governo federal. Gabardo (2009, p. 219), ao analisar sua configuração histórica, explica as razões desses níveis de atuação prioritária a partir da vinculação do princípio à doutrina social da Igreja Católica:

A doutrina social da Igreja sempre concentrou seu discurso no sentido funcional da subsidiariedade, exigindo seu cumprimento para a ação estatal. E isso se justifica plenamente, considerando o momento histórico em que o princípio passou a ser desenvolvido no século passado. No primeiro quartel do século Xx observa-se um quadro de surgimento de Estados totalitários, nacionalistas exacerbados, ampliação da atuação do Estado na economia, crescente flexibilização da noção de propriedade e surgimento de Constituições de caráter social. Frente a esta situação, torna-se necessário para a Igreja colocar-se na defesa de princípios de caráter liberal, tanto no tocante à questão econômica quanto política. Particularmente, o avanço da doutrina socialista torna-se um importante propulsor da nova doutrina católica para a teoria do Estado, avessa ao "coletivismo", mas sem eximir-se da figura do Estado. A tese da subsidiariedade enquadrou-se perfeitamente nos objetivos de flexibilidade conjuntural, necessária para a oposição ao socialismo sem a exagerada e não mais apropriada recusa, tipicamente liberal, da legitimidade interventiva estatal.

Como princípio jurídico, a subsidiariedade configura-se de modo muito complexo, prestando a interpretações tanto no sentido de um centralismo comunitário, quanto no sentido da autonomia das unidades subnacionais (Morais, 1999). Na teoria jurídica brasileira há vigoroso debate sobre a previsão ou não do princípio da subsidiariedade na 
Constituição Federal de 1988 (Gabardo, 2009; Zimmermann, 2005; Bercovici, 2003; Torres, 2001). Apesar desse debate, podemos afirmar que, na área de educação, a Constituição Federal de 1988 em seus artigos 211,212 e 213 informam princípios de subsidiariedade, além das Emendas Constitucionais n. 14/96 e n. 53/06, que regulamentam respectivamente o Fundo de Manutenção e Desenvolvimento do Ensino Fundamental (FUNDEF) e o Fundo de Manutenção e Desenvolvimento da Educação Básica e de Valorização dos Profissionais da Educação (FundeB).

Nesse sentido, tanto para Gabardo (2009) quanto para Bercovici (2003), a combinação da doutrina social da Igreja com as mais distintas correntes neoliberais recentes tem configurado a subsidiariedade como critério determinante dos fins econômicos e sociais do Estado, mediante a despolitização das decisões, a pretensão de neutralidade e uma postura menos interventiva do Estado. Bercovici (2003) afirma que, no contexto neoliberal, o princípio da subsidiariedade ganha relevo como característica fundamental do Estado federal associado à eficiência e à otimização das funções públicas melhor realizadas nas esferas de atuação das unidades subnacionais, mediante mecanismos de descentralização e desestatização. Gabardo (2009, p. 212-213) indica que a subsidiariedade não é neutra, ao contrário, é uma opção política:

Para a Teoria do Estado e para o Direito público, por um lado subsidiariedade significa "descentralização" propriamente dita, por outro significa "privatização" no tocante à organização estatal e no tocante ao exercício das atividades públicas. No primeiro sentido, que também pode ser chamado de "orgânico", a ideia de atuação subsidiária reporta-se à preferência que deve ser conferida, por princípio, à atuação no menor núcleo de capacidade. A competência para o exercício da função é atribuída ao organismo mais próximo da questão tratada. Nesta acepção, a subsidiariedade torna-se o critério de determinação da descentralização política e/ ou administrativa, pelo que se justifica de "vertical". A subsidiariedade como descentralização (sentido orgânico ou vertical) pode ser representada mediante a seguinte proposição: "o que pode ser feito pela cidade não deve ser feito pela região, o que pode ser feito pela região não deve ser feito pelo poder central". No segundo sentido, que além de horizontal também pode ser chamado de funcional, a noção de subsidiariedade refere-se ao protagonismo do indivíduo e da sociedade civil na consecução das atividades que lhe são necessárias, relegando aos organismos institucionais público-estatais uma competência de caráter acessório (complementar e/ou suplementar). 
Talvez pela dinâmica extremamente fragmentada e aligeirada das conferências municipais e estaduais, tanto os documentos que antecederam à CONAE quanto o Documento Final resultante do evento não puderam ser debatidos com maior vigor político, teórico e técnico, não expressando avanços para o início de uma proposta consistente de pacto federativo no âmbito educacional. ${ }^{7}$ As discussóes da CONAE parecem não ter abordado com a necessária profundidade as questôes relativas à organização da educação nacional, ao regime de colaboração e à própria constituição de um "Sistema Nacional e Articulado de Educação", que seria a proposta principal do novo PNE. Os documentos parecem sinalizar não a definição de um regime de colaboração, mas corroborar formas de coordenação vertical ${ }^{8}$ já existentes, inclusive o princípio da subsidiariedade que, como vimos, pode potencializar os graves problemas de descentralização com desestatização e privatização presentes na política educacional brasileira das últimas décadas.

A CONAE e o "Sistema Nacional e Articulado de Educação": (in)definições e (in)consequências para o novo Plano Nacional de Educação

Os contornos dos conflitos federativos no Brasil, por falta de regulamentação do regime de colaboração, se tornaram ainda mais complexos e assumiram duas dimensões: uma vertical e outra horizontal. A vertical se traduz na atitude defensiva do governo federal ou livrandose de encargos com extinção de sua intervenção, ou incentivando programas de descentralização, nos quais assume postura de fiscalizador dos processos. A dimensão vertical dos conflitos federativos no Brasil também pode ser tipificada mediante a ação competitiva e predatória dos entes federados (estados e municípios) na disputa com o governo federal por recursos, gerando agenda de demandas segmentadas e fragmentadas que só agravam os conflitos. $\mathrm{Na}$ dimensão horizontal, a "guerra fiscal" é exemplo clássico de conflitos entre os entes federados, dada a dificuldade de articulação e coordenação do governo federal (Silva \& Costa, 1995). Na educação, é possível observar a dimensão horizontal do conflito com a desresponsabilização dos entes federados para garantia de medidas de acesso, permanência e qualidade nas etapas e modalidades da educação básica. 
A Portaria CNE/CP n. 10, de 6 de agosto de 2009, com o objetivo de iniciar os debates para dar sustentação às discussões para o novo PNE, indica que, a partir da avaliação do PNE (2001-2010), um dos principais problemas externos à consecução das metas do referido Plano foi a ausência de normatização do SNE e do regime de colaboração. Dessa forma, salienta que o novo PNE deve avançar na superação desses entraves:

Na organização da Educação Nacional, o novo PNE precisa avançar, no sentido de dar maior organicidade às suas ações. Para tanto, há que estabelecer: o Sistema Nacional de Educação, como forma de garantir a unidade na diversidade; o regime de colaboração, no tocante à educação, que delimitará com propriedade e clareza os limites e responsabilidades de cada ente federado; a composição, atribuições e funcionamento dos órgãos colegiados dos sistemas e das escolas, abrindo espaço para a participação da sociedade, desde o Fórum Nacional de Educação, o Conselho Nacional - CNE, passando pelos Conselhos Estaduais e Municipais, chegando até ao Conselho Escolar. Nesse contexto, certamente a Lei de Diretrizes e Bases da Educação (Lei n. 9.394/96) deverá ser revista, especialmente, no Título IV, que trata da Organização da Educação Nacional. (Brasil, 2009, p. 10)

Assim, o documento parece indicar que o regime de colaboração para a área de educação deve regulamentar: a) limites e responsabilidades dos entes federados; b) os órgãos colegiados dos sistemas (no plural) e das escolas com o envolvimento/participação num fórum nacional de educação (a ser constituído), dos conselhos nacionais, estaduais e municipais de educação, bem como dos conselhos escolares.

Da forma como se apresenta, a Portaria não avança no sentido da definição de quais seriam as atribuições e as formas de articulação dos entes federados, bem como na indicação mais efetiva sobre atribuições, composição e formas de articulação entre o fórum e os órgãos colegiados, o que pode se constituir, em vez de solução, em mais um imbróglio federativo.

Outro aspecto digno de nota na Portaria é que a mesma não questiona, ao contrário, parece estimular o princípio de subsidiariedade e dos conflitos verticais presentes na Constituição Federal de 1988 e na Lei de Diretrizes e Bases (LDB), ao prescrever que as metas no novo PNE devem conter o estímulo à organização dos sistemas municipais de ensino, orientando-os a constituir conselhos que se tornem órgãos normatizadores do ensino público municipal e das instituições privadas de 
Constituição, Federação e propostas para o novo Plano Nacional de Educação...

educação infantil; bem como a implementação do Sistema Nacional de Avaliação da Educação Básica voltado para subsidiar o processo de gestão educativa e para garantir a melhoria da aprendizagem e dos processos formativos, medidas estas que vêm sendo conduzidas pelo governo federal há décadas, sem qualquer ação consequente na melhoria do acesso, da permanência e da qualidade do ensino.

O Documento Referência da CONAE se estruturou a partir de seis eixos temáticos, o primeiro deles, e talvez o mais relevante, foi o "Papel do Estado na Garantia do Direito à Educação de Qualidade: Organização e Regulação da Educação Nacional”. Além de reiterar a denúncia da ausência de regulamentação do regime de colaboração, argumenta que um sistema nacional e articulado passa, necessariamente, pela definição desse instituto jurídico-político, mencionando, inclusive, que o regime de colaboração se traduziria na corresponsabilidade entre os entes federados, o que, aparentemente, avança em relação à Portaria $\mathrm{CNE} / \mathrm{CP}$ n. 10. Entretanto, a reiteração do princípio de subsidiariedade é destacada em vários trechos do Documento Referência, afirmando, inclusive, mecanismos desse princípio já existentes no ordenamento jurídico brasileiro, como no trecho a seguir:

Para a existência do Sistema Nacional de Educação, é fundamental que os órgãos legislativos (Câmara e Senado) e Executivo (MEC) estabeleçam políticas educacionais, traduzidas em diretrizes e estratégias nacionais, planos nacionais, programas e projetos, coordenando e apoiando técnica e financeiramente, de forma suplementar, as ações dos diversos sistemas de ensino, visando a alcançar os objetivos da educação nacional, auxiliado por um órgão normatizador de Estado (CNE) que garanta a unidade na diferença. (...). Assim, uma legislação comum (LDB e PNE) e normas comuns (pareceres e resoluçôes do CNE), de certa forma, já existentes na atualidade, garantem a base e a possibilidade, também presente na Constituiçāo Federal, de que "a União, os estados, o Distrito Federal e os municipios organizem, em regime de colaboração, os seus sistemas de ensino" (art. 211), indicando normas específicas e complementares, que auxiliem no cumprimento da legislação nacional, por meio de seus conselhos específicos (estaduais, distrital e municipais). (CONAE, 2009, p. 13-14; grifos nossos)

O Documento Final da CONAE, realizada no período de 28 de março a $1^{\circ}$ de abril de 2010, em Brasília (DF), modifica muito pouco ou quase nada as recomendações do Documento Referência quanto às temáticas da constituição do SNE e da regulamentação do regime 
de colaboração. Logo na introdução, o documento afirma que a Conferência constituiu-se num espaço democrático de construção de acordos entre atores sociais, tanto para o debate sobre as perspectivas para a organização da educação nacional, quanto para a formulação do PNE 2011-2020 (CONAE, 2010). A partir dessa avaliação do evento, o documento afirma que: "Nessa direção, a CONAE representou um exemplo do princípio constitucional do regime de colaboração e construiu um patamar histórico para a efetivação do Sistema Nacional de Educação no Brasil".

Evidentemente é inegável a magnitude do debate sobre o novo PNE nos municípios, estados e na CONAE, mas, efetivamente, não se pode considerar a organização do evento como exemplo do regime de colaboração por se tratar de iniciativa de coordenação federativa da União, na qual os entes federados e a sociedade civil foram chamados a tomar parte. É importante ressaltar que nas condiçōes nebulosas, fragmentadas e dispersas do arranjo federativo brasileiro a tarefa de coordenação da União pode, no contexto atual, ser de extrema relevância, mas não se pode perder de vista que o regime de colaboração prevê a cooperação tanto vertical, quanto horizontal dos entes federados com mecanismos de interpenetração e não de interdependência e, ainda mais importante, no caso brasileiro, com mecanismos bem definidos de redistribuição de recursos e competências.

Outra questão bastante curiosa é a inversão que o documento traz quanto à articulação entre a constituição do SNE e o instituto jurídico do regime de colaboração. No documento, encontramos as seguintes assertivas: a) "Assim, o SNE é entendido como mecanismo articulador do regime de colaboração no pacto federativo, que preconiza a unidade nacional, respeitando a autonomia dos entes federados" (CONAE, 2010, p. 14) e b) "o Plano deve ser entendido como uma das formas de materialização do regime de colaboração entre sistemas e de cooperação federativa" (idem, ibid., p. 35).

Ora, se o diagnóstico inicial do insucesso do atual PNE foi exatamente a ausência de regulamentação do regime de colaboração, como o sistema pode ser um mecanismo articulador do regime de colaboração, se a ausência de regulamentação é exatamente o "nó górdio" da Federação brasileira e, talvez, o maior empecilho para a consolidação de políticas educacionais de caráter efetivamente nacional? 
Ademais, há, no Documento Final da CONAE, assim como do Documento Referência, uma indistinção entre coordenação federativa e regime de colaboraçãa. A coordenação federativa é elemento do regime de colaboração, mas não são sinônimos. Essa indistinção pode ser observada na seguinte meta:

Construção do Sistema Nacional de Educação que garanta uma política nacional comum, cabendo à União coordenar essa política, articulando os diferentes níveis e sistemas de ensino e exercendo função normativa, redistributiva e supletiva em relação às demais instâncias educacionais, sem prejuízo das competências próprias de cada ente federado. Esse sistema deverá contar com a efetiva participação da sociedade civil e da sociedade política na garantia do direito à educação.

Além disso, essa meta reitera o princípio da subsidiariedade, uma vez que reafirma a ação supletiva da União, a indefinição do que seria essa coordenação e a "efetiva participação da sociedade civil", conceito bastante flexível que pode abarcar extremos, desde grupos empresariais, como o "Compromisso Todos Pela Educação", a movimentos sociais, como a "Via Campesina", por exemplo.

No Documento Final da CONAE, a única prescrição mais clara quanto ao regime de colaboração e que apresenta algum potencial para iniciar um debate denso sobre a sua regulamentação é a seguinte:

A regulamentação do Regime de Colaboração deve explicitar a participação da União na cooperação técnica e, especialmente, na determinação de transferências regulares e contínuas de recursos financeiros às instituições públicas dos estados, DF e municípios, priorizando os entes federados com baixos índices de desenvolvimento socioeconômico e educacional, tendo como critérios indicadores o IDH, altas taxas de pobreza, índice de fragilidade educacional na oferta de EJA, entre outros, que permitam indicar aqueles que mais demandam apoio para a garantia do custo aluno/a-qualidade (CAQ). Esta regulamentação deve, ainda, prever meios de superação das desigualdades regionais, especialmente por meio da construção de uma política de financiamento, ancorada na perspectiva do CAQ. (CONAE, 2010, p. 23)

Dessa forma, exige explicitação do papel da União na cooperação técnica e na determinação de transferências de recursos que podem equalizar as graves desigualdades regionais e intraestatais, estabelecendo uma cooperação vertical que permite alguma incidência na questão 
do federalismo fiscal, significando um caminho aberto para o estabelecimento futuro de cooperações horizontais entre os entes federados.

\section{Conclusões}

Com a pouca densidade teórica, política e jurídica sobre a regulamentação do regime de colaboração constatada nos documentos que serviram de suporte à CONAE, bem como no Documento Final originado da mesma para a elaboração do novo PNE (2011-2020) e considerando a conjuntura de final de mandato para executivos e legislativos no plano federal e estaduais, acreditamos que é temeroso definir e dar consequência a um processo para uma efetiva regulamentação do regime de colaboração da educação brasileira. Isso exigiria um novo esforço político para repactuar a Federação brasileira, incidindo tanto sobre os conflitos verticais, quanto sobre os horizontais, além da exigência de um debate mais acurado sobre o princípio da subsidiariedade presente nos dispositivos referentes às matérias educacionais que contradizem o caráter social da Carta Magna.

É importante destacar que a experiência histórica da Assembléia Nacional Constituinte tem muito a contribuir, no sentido da necessária cautela no tratamento e no debate sobre a regulamentação do regime de colaboração. Da mesma forma que a bandeira da descentralização federativa e municipalista - com forte pressão das unidades subnacionais - foi erguida com imediatismo e com pouca reflexão sobre seus impactos e consequências para a Federação brasileira, o mesmo pode acontecer com a bandeira da regulamentação do regime de colaboração para a educação, só que, dessa vez, erguida pelo poder central (governo federal) e com fortes indícios de indistinção entre coordenação federativa e regime de colaboração, bem como de manutenção do princípio da subsidiariedade, que só pode ter algum sentido em federaçōes relativamente simétricas, como é o caso da Alemanha.

Dessa forma, parece prudente, no cenário atual, garantir a prescrição quanto ao papel da União na cooperação técnica, na determinação de mecanismos de redistribuiçãao e quanto à garantia de um custo aluno-qualidade, o que, de uma forma modesta - porém direta e, talvez, mais efetiva -, contribuiria, posteriormente, para o aprofundamento do debate sobre a regulamentação mais adequada do regime de 
colaboração e, em consequência, para a configuração de um Sistema Nacional de Educação.

No processo de regulamentação do regime de colaboração, há que se levar em conta um grande desafio para as relações intergovernamentais no Brasil: o estabelecimento de uma justa distribuição de poder, autoridade e recursos entre os entes federados, garantindo a independência e interpenetração dos governos nacional e subnacionais sem que haja comprometimento de um projeto de desenvolvimento nacional, no qual um dos elementos é a educação.

Esse desafio é constitucional, na medida em que os incisos II e III do artigo $3^{\circ}$ da Constituição Federal de 1988 estabelecem como objetivos fundamentais da República Federativa a garantia do desenvolvimento nacional e a erradicação das desigualdades sociais e regionais. Reiterando essa lógica, o parágrafo $1^{\circ}$ do artigo 174 preconiza que "A lei estabelecerá as diretrizes e bases do planejamento do desenvolvimento nacional equilibrado, o qual incorporará e compatibilizará os planos nacionais e regionais de desenvolvimento". Obviamente que a elevação do nível educacional e cultural integra o planejamento e o desenvolvimento nacional. Esses dispositivos estariam, ainda, informados pela compreensão de que o desenvolvimento é um legítimo princípio constitucional da ordem econômica, sendo, portanto, mais do que mero objetivo, compondo um modelo econômico propugnado pela Constituição Federal de 1988, que é o do Estado de bem-estar social no plano jurídico-normativo (Grau, 2002).

$\mathrm{Na}$ relação entre a Constituição Federal, o modelo de Federação brasileiro e a o novo Plano Nacional de Educação, com a sua proposta precípua de constituição de um Sistema Nacional de Educação, talvez caiba, do ponto de vista normativo, ampliar o debate no sentido da substituição do princípio da subsidiariedade pelo princípio da "exata adequação" (Quadros, 1995), ou seja, o critério de distribuição das competências e recursos na área de educação não deve ser o da instância federativa maior ou menor, mas sim do ente federado que melhor pode realizar a competência, o que poderia configurar uma relação solidária e não predatória entre os entes federados.

Recebido e aprovado em agosto de 2010. 


\section{Notas}

1. É importante não confundir a proposição de uma Federação tetradimensional feita por doutrinadores como Paulo Bonavides (2004) com a característica da Federação brasileira, cuja base é trina ou, como preferimos, tridimensional. A primeira considera que o federalismo das regiōes seria a única alternativa para a crise do federalismo brasileiro na atualidade. Essa corrente considera os apelos ao regime de colaboração confortáveis, porém ingênuos. Bonavides (2004) argumenta que a região, como quarta instância federada, funcionaria tanto como mecanismo de controle da centralização do governo federal, como de descentralização das instâncias subnacionais.

2. Comissão da organização do Estado; Comissão da família, da educação, cultura e esportes, da ciência e tecnologia e da comunicação; Subcomissão da União, Distrito Federal e Territórios; Subcomissão de municípios e regiōes; e Subcomissão da educação, cultura e esportes.

3. Vale ressaltar que a redação original foi modificada, colocando no plural a possibilidade de regulamentação desse instituto: "Parágrafo único. Leis complementares fixarão normas para a cooperação entre a União e os Estados, o Distrito Federal e os Municípios, tendo em vista o equilíbrio do desenvolvimento e do bem-estar em âmbito nacional" (Redação dada pela Emenda Constitucional n. 53, de 2006; grifos nossos).

4. Na atualidade, o federalismo alemão também atravessa uma crise advinda da reunificação, dos processos de globalização e da integração à União Européia. Para mais detalhes, conferir Schultze (2001).

5. Criação de seguro obrigatório para acidentes de trabalho, doenças, invalidez e velhice (Gabardo, 2009).

6. Nascido em Trier, Alemanha, em uma família aristocrática, Oswald Von Nell-Breuning foi ordenado sacerdote em 1921 e nomeado professor de Ética na Universidade de Frankfurt, em 1928. Desempenhou importante papel na elaboração da Encíclica Quadragesimo Anno (1931) do Papa Pio xI, que abordou a questão social e desenvolveu o princípio da subsidiariedade.

7. Dificuldade adicional é a pouca quantidade de estudos desenvolvidos sobre a relação entre o federalismo e a educação no Brasil. Como exemplos, podemos citar Cury $(2007,2008)$ e, recentemente, Oliveira e Santana (2010).

8. A coordenação federativa se distingue da colaboração, uma vez que a coordenação é procedimento que busca resultado comum, apesar da autonomia dos entes federados (Bercovici, 2003).

\section{Referências}

BERCOVICI, G. Desigualdades regionais, Estado e Constituição. São Paulo: Max Limonad, 2003. 
Constituição, Federação e propostas para o novo Plano Nacional de Educação...

BONAVIDES, P. A Constituição aberta: temas políticos e constitucionais da atualidade, com ênfase no Federalismo das regiōes. 2. ed. São Paulo: Malheiros, 2004.

BRASIL. Assembléia Nacional Constituinte. Comissão de Organização do Estado. Subcomissão da União, Distrito Federal e Territórios. Relatório e anteprojeto. Brasília, DF, 1987a. 33f.

BRASIL. Assembléia Nacional Constituinte. Comissão de Organização do Estado. Subcomissão de Municípios e Regiōes. Relatório. Brasília, DF, 1987b. 43f.

BRASIL. Assembléia Nacional Constituinte. Comissão da Família, da Educação, Cultura e Esportes, da Ciência e Tecnologia e da Comunicação. Subcomissão da Educação, Cultura e Esportes. Relatório. Brasília, DF, 1987c. 49f.

BRASIL. Ministério da Educação, Conselho Nacional de Educação. Portaria CNE/CP n. 10, de 6 de agosto de 2009. Diário Oficial da Uniāo, Brasília, DF, 2009.

CAMARGO, A. Federalismo cooperativo e o princípio da subsidiariedade: notas sobre a experiência recente do Brasil e da Alemanha. In: Hofmeister, W.; Carneiro, J.M.B. (Org.). Federalismo na Alemanha e no Brasil. São Paulo: Fundação Konrad Adenauer, 2001. p. 6994. (Debates n. 22).

CASSINI, S.A. Federação e educação no Brasil: debates e tentativas de regulamentação do regime de colaboração pós-constituiçãao de 1988 . 2010. 109f. Projeto de Qualificação (Mestrado) - Programa de Pós-Graduação em Educação, Universidade Federal do Espírito Santo, Vitória.

CONFERÊNCIA NACIONAL DE EDUCAÇÃO (CONAE), 2010, Brasília, DF. Construindo o Sistema Nacional Articulado de Educação: o Plano Nacional de Educação, diretrizes e estratégias de ação; Documento Referência. Brasília, DF: MEC, 2009.

CONFERÊNCIA NACIONAL DE EDUCAÇÃO (CONAE), 2010, Brasília, DF. Construindo o Sistema Nacional Articulado de Educação: o Plano Nacional de Educação, diretrizes e estratégias de ação; Documento Final. Brasília: DF: MEC, 2010. 
CURY, C.R.J. Federalismo político e educacional. In: Ferreira, N.S.C.; Schelesener, A. (Org.). Políticas públicas e gestão da educação: polêmicas, fundamentos e análises. Brasília, DF: Liber Livro, 2007. p. 113-129.

CURY, C.R.J. Sistema Nacional de Educação: desafio para uma educação igualitária e federativa. Educação \& Sociedade, Campinas, v. 29, n. 105, p. 1187-1209, dez. 2008.

GABARDO, E. Interesse público e subsidiariedade: o Estado e a sociedade civil para além do bem e do mal. Belo Horizonte: Fórum, 2009 .

GRAU, E.R. A ordem econômica na Constituição de 1988. 7. ed. São Paulo: Malheiros, 2002.

KUGELMAS, E. A evolução recente do regime federativo no Brasil. In: Hofmeister, W.; Carneiro, J.M.B. (Org.). Federalismo na Alemanha e no Brasil. São Paulo: Fundação Konrad Adenauer, 2001. p. 29-50. (Série Debates n. 22).

LIJPHART, A. Modelos de democracia: desempenho e padrão de governo em 36 países. Rio de Janeiro: Civilização Brasileira, 2003.

LOPREATO, F.L.C. O colapso das finanças estaduais e a crise da Federação. São Paulo: UNESP, 2002.

MEDICI, A.C. Políticas sociais e federalismo. In: Affonso, R.B.A.; Silva, P.L.B. (Org.). Federação em perspectiva: ensaios selecionados. São Paulo: FUNDAP, 1995. p. 285-304.

MORAIS, C.B. O princípio da subsidiariedade na ordem constitucional portuguesa. In: Barros, S.R.; Zilveti, F.A. (Org.). Direito constitucional: estudos em homenagem a Manoel Gonçalves Ferreira Filho. São Paulo: Dialética, 1999. p. 36.

OLIVEIRA, R.P.; SANTANA, W. Educação e federalismo no Brasil: combater as desigualdades, garantir a diversidade. Brasília, DF: UNESCO, 2010 .

QUADROS, F. O princípio da subsidiariedade no direito comunitário após o tratado da União Européia. Coimbra: Almedina, 1995. 
SCHULTZE, R.O. Tendências da evolução do federalismo alemão: dez teses. In: Hofmeister, W.; Carneiro, J.M.B. (Org.). Federalismo na Alemanha e no Brasil. São Paulo: Fundação Konrad Adenauer, 2001. p. 13-28. (Debates n. 22).

SILVA, P.L.B.; COSTA, V.L.C. Descentralização e crise da Federação. In: Affonso, R.B.A.; Silva, P.L.B (Org.). Federação em perspectiva: ensaios selecionados. São Paulo: FUndAP, 1995. p. 261-283.

SOUZA, C. Federalismo e descentralização na constituição de1988: processo decisório, conflitos e alianças. Dados: Revista de Ciências Sociais, São Paulo, v. 44, n. 3, p. 513-560, 2001.

TORRES, S.F. O principio da subsidiariedade no Direito Público contemporâneo. Rio de Janeiro: Renovar, 2001.

ZIMMERMANN, A. Teoria geral do federalismo democrático. Rio de Janeiro: Lumen Juris, 2005. 